\title{
Functional association of oestrogen receptors with HPV infection in cervical carcinogenesis
}

\author{
Balaji Ramachandran \\ Department of Molecular Oncology, Cancer Institute (W.I.A.), Adyar, Chennai, India
}

Correspondence should be addressed to B Ramachandran Email

balajiphd@gmail.com

\begin{abstract}
Repeated parity and usage of oral contraceptives have demonstrated an increased risk of cervical cancer (CC) in HPV-infected women. These lifestyle observations raise the likelihood that oestrogens and HPV infection might act synergistically to affect cancers of the cervix. In vivo studies have indicated the requirement of oestrogens and ER $\alpha$ in the development of atypical squamous metaplasia followed by cervical intraepithelial neoplasia (CIN) I, II and III. CIN II and III are precancerous cervical lesions that can progress over time to CC as an invasive carcinoma. Recently, there has been evidence suggesting that ERo signalling in the tumour epithelium is a preliminary requisite during cancer initiation that is subsequently lost during tumorigenic progression. Conversely, continued expression of stromal ER $\alpha$ gains control over tumour maintenance. This review summarises the current information on the association between oestrogens and HPV infection in contributing to CC and the possibility of SERMs as a therapeutic option.
\end{abstract}

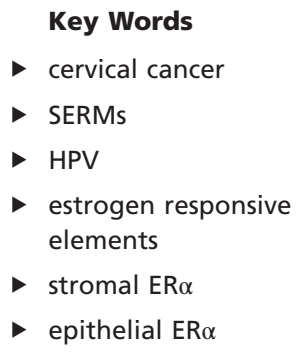

\section{Introduction}

The uterine cervix, uterus, ovaries and breast constitute the hormone-responsive tissues of the human female physiology (Diel 2002, Chung et al. 2010). Neoplastic transformation of these tissues, except the cervix, is well recognised to be highly influenced by oestrogen hormones that control proliferation, apoptosis, migration and metastasis (King 1991, Henderson \& Feigelson 2000, Ramachandran et al. 2011). The uterine cervix is also a part of the female reproductive system. However, the role of oestrogens in human CC has not yet been well-defined (Chung et al. 2010). Currently, with the epidemiological evidence linking multi-parity and oral contraceptive usage to an increase in CC risk, oestrogens have been speculated to be involved in the development of cervical carcinogenesis (Moreno et al. 2002, Muñoz et al. 2002, Roura et al. 2016). Nevertheless, such carcinogenic transformations due to oestrogens are not physiological and involve a synergistic combination with infection of high-risk human papilloma virus (HPV) as the strongest factor (Brake \& Lambert 2005, Chung et al. 2008, Marks et al. 2011, 2015, Liao et al. 2012). The successful initiation of HPV-dependent carcinogenesis begins with the infection of HPV in episomal form, initiating the transcription of viral gene products, followed by subsequent genomic integration of HPV oncogenes into the host genome (Senapati et al. 2016). The highly potent viral oncogenes express E6 and E7 oncoproteins that bind to p53 and Rb, respectively, and surpass the host defence system (Moodley et al. 2003, Sima et al. 2008, Chung et al. 2010). Therefore, it can be hypothesised that an endogenous or exogenous surge of oestrogens could stimulate the viral machinery and concomitantly 
encourage hormone-dependent progression of uncontrolled proliferation of a clonal population of cells contributing to cancer of the uterine cervix. This review features the current information regarding the role of oestrogens in the amplification of HPV-positive CC.

\section{HPV involvement}

In the case of genital cancers, an HPV infection is most commonly a sexually transmitted infection (https:// monographs.iarc.fr/ENG/Classification/Table4.pdf). In addition, several cancers of diverse anatomical regions were associated with different transmission routes of HPV infection (https://monographs.iarc.fr/ENG/Classification/ Table4.pdf). HPV particles are non-enveloped and assume an icosahedral structure, with a diameter of $55 \mathrm{~nm}$ and enclose an $8 \mathrm{~kb}$ long double-stranded DNA (Chung et al. 2010, Doorbar et al. 2015). Clinical, molecular and epidemiological investigations have demonstrated that CC is caused by persistent infection with high-risk HPV, where part of the viral DNA sequence becomes integrated into the host genome (Brake \& Lambert 2005, Chung et al. 2008, Marks et al. 2011, 2015, Liao et al. 2012). The peak time for a woman to acquire an HPV infection is during the sexually active phase of life (http://www. who.int/mediacentre/factsheets/fs380/en/). Typically, 90\% of HPV infections are cleared within two years (http://www.who.int/mediacentre/factsheets/fs380/en/). Only a small proportion of the HPV infection persists, and several risk factors have been associated with HPV persistence and subsequent development of CC (http:// www.who.int/mediacentre/factsheets/fs380/en/). Genital HPV is classified into high-risk and low-risk types. Lowrisk HPV generally causes only benign lesions, whereas the high-risk type accounts for immortalisation and malignant transformation of the infected cells. There are 13 HPV types $(16,18,31,33,35,39,45,51,52,56$, 58, 59 and 66) categorised as group 1 carcinogens to humans (https://monographs.iarc.fr/ENG/Monographs/ vol90/mono90-10.pdf). Two principal HPV types (16 and 18) cause $70 \%$ of precancerous cervical lesions and CC (http://www.who.int/mediacentre/factsheets/fs380/en/). Some of the early genes of HPV, namely E5, E6 and E7 oncogenes, promote malignant cell transformation by interacting with several host cellular proteins essential for cell cycle control (Münger et al. 2004). Two viral oncogenes, E6 and E7, are invariably expressed in human $\mathrm{CC}$, and their continued expression is required for the maintenance of the cancerous state (Münger et al. 2004).
The strong tumorigenic potential of high-risk HPVs stems from the ability of the E6 and E7 oncoproteins to inactivate potent tumour suppressor proteins, p53 and $\mathrm{Rb}$, respectively (Moodley et al. 2003, Sima et al. 2008). After the successful establishment of infection, HPV early viral oncogenes are expressed in both the episomal and integrated forms and alter normal cell cycle functionality, telomere maintenance and chromosomal stability and modulate apoptosis through a variety of pathways. In addition, cofactors such as nutrients, tobacco smoke, presence of other infections and radiation and events such as alterations of proto-oncogenes are also known to be associated with the development of CC (https:// monographs.iarc.fr/ENG/Monographs/vol90/mono90-9. pdf, Münger et al. 2004, Lagunas-Martínez et al. 2010, Moody \& Laimins 2010). However, the requirement of these cofactors for complete cellular transformation in CC has not yet been demonstrated.

\section{Role of endogenous and exogenous oestrogens}

The cervix is an oestrogen-responsive tissue. In particular, the transformation zone of the uterine ectocervix, which serves as the site of initiation of tumorigenesis, is highly sensitive to steroid hormone stimulation (Remoue et al. 2003). There is a consistent association between the degree of steroid hormone contraceptive usage, repeated fullterm pregnancies and HPV infection and an increased risk of developing CC (Moreno et al. 2002, Muñoz et al. 2002, Chung et al. 2010, Marks et al. 2011, 2015, Liao et al. 2012, Roura et al. 2016). Several investigators have shown that the mere presence of an HPV infection is not a mandate to develop CC. Additional synergistic factors, such as oestrogens, may be required to induce HPV-dependent carcinogenesis (Chung et al. 2008, 2010, Shai et al. 2008).

Prospective studies have demonstrated that usage of oral contraceptives in individuals with existing dysplasia for more than six years show a greater risk of progression from cervical dysplasia to carcinoma in situ. It is speculated that steroid hormones could increase the transcription of important HPV oncogenes, resulting in the degradation of p53, disrupting the normal cell cycle and eventually leading to CC (Moodley et al. 2003). An IARC multi-centric study performed a pooled analysis from eight case-control studies and interpreted that long-term use of oral contraceptives as a cofactor can increase the risk of cervical carcinoma up to four-fold in HPV-positive women (Moreno et al. 2002). Another IARC 
multi-centric study performed a pooled analysis of the epidemiological data collected from several case-control studies conducted in four different continents and indicated that multiple pregnancies could increase the risk of squamous cell carcinoma of the cervix in HPV-infected women (Muñoz et al. 2002). Gierisch and coworkers (Gierisch et al. 2013) made a systematic review of 12 CC studies conducted after the year 2000. This criterion was chosen to maximise the number of subjects who could have used the current oral contraceptive formulations available in the market. An increased risk of CC associated with the duration of oral contraceptive use was observed in women with an HPV infection (Gierisch et al. 2013). Therefore, these observations raise the likelihood that hormones such as oestrogen, in the presence of an HPV infection, might affect cancers of the cervix.

\section{Putative hormone responsive element-like sequences within host-integrated HPV genome}

Oestrogen is believed to transactivate viral oncogenes, leading to an increase in viral persistence and gene expression (Mitrani-Rosenbaum et al. 1989). The transformation zone of the cervix, which is very sensitive to oestrogens, is where most cases of CC arise; certain sequences that are found in the HPV genome resemble oestrogen-controlled sequences (Elson et al. 2000, Remoue et al. 2003). The long control region (LCR) of the HPV-integrated viral genome plays a regulatory function in controlling transcription of E6 and E7. Viral and cellular transcription factors are believed to recognise specific regions in the LCR and affect viral gene transcription (Garcia-Carranca et al. 1988). The viral transcription factor E2 is frequently disrupted in cervical carcinomas during integration of the viral genome into the host genome (Schwarz et al. 1985). Hence, in invasive tumours where the HPV LCR is no longer in an episomal form, the only alternative is that the cellular transcription factors, including receptors for steroid hormones, could either upregulate or downregulate the transcription of viral oncogenes (Mitrani-Rosenbaum et al. 1989, MoralesPeza et al. 2002, Doorbar et al. 2015). Gene expression via the HPV 16 LCR was observed to be upregulated in the study by Chen and coworkers in response to natural and synthetic oestrogens, suggesting the presence of hormonal responsiveness within the LCR (Chen et al. 1996). Indeed, this study has several limitations such as use of the supraphysiological concentration of oestradiol
$(100 \mathrm{nM})$, which neither represents a physiological (1-10nM) nor a pharmacological concentration (more than $10 \mu \mathrm{M}$ ) of oestradiol. Most of the synthetic oestrogen and progesterone used in this study failed to significantly transactivate the HPV 18 LCR. In addition, the anti-oestrogen tamoxifen increased LCR-driven gene expression, but no explanation was provided for this result. Furthermore, no statistical analyses were performed.

Oestrogen can exert control over nuclear mechanisms by interacting through an activated ER-oestrogen complex with specific DNA regulatory sequences known as oestrogen-responsive elements (ERE) present in the LCR (Chen et al. 1996, Burk et al. 2003). Two glucocorticoid response elements (GREs) at positions 7477-7491 and 7643-7657 in the LCR region, as well as a number of GREs and EREs, have been identified within the HPV 16 genome. However, the functional significance of these responsive elements was not studied (Chan et al. 1989, Mittal et al. 1993, Burk et al. 2003). In the HPV genome, the specific mechanism by which oestrogen might contribute to cervical neoplasia is unknown. The $1-\mathrm{kb}$ promoter of HPV has been shown to contain palindromic EREs. Indeed, seven different regions with a high degree of similarity to the ERE consensus sequence have been identified ( $5^{\prime}$ GGTCANNNTGACC3'), and these sequences are half, incomplete or partial palindromes. These sequences are found within the HPV genome, which might possibly enhance transcription of the viral genome upon stimulation with the activated oestrogen-ER complex (Mitrani-Rosenbaum et al. 1989, Moodley et al. 2003, Baldwin et al. 2006). Limitations of the study by Mitrani-Rosenbaum and coworkers are that they did not detect a notable involvement of functional EREs in the HPV genome, and their study did not include HPV 18, the other high-risk subtype. Transcription factor-binding sites were recognised in HPV 18 variants with distinct functional activities (López-Saavedra et al. 2009). Apart from the LCR, the non-coding upstream regulatory region (URR) of HPV also harbours responsive elements that serve as target sites to potentially bind to cellular factors (Chan et al. 1989, Mitrani-Rosenbaum et al. 1989, Chen et al. 1996). The URR appears to be inducible upon treatment with exogenous oestrogen, leading to neoplastic transformation at the squamocolumnar junction of the cervix in the HPV-18 URR E6/E7 transgenic mouse model (Park et al. 2003). ERs are also known to bind to variants of common response element such as GRE (5'GGTACANNNTGTTCT3') elements that differ by two base pairs from ERE in each half site (Klinge 
2001). In addition, HPV oncogenes were predicted to deregulate direct coactivators such as SRC-1 and disrupt hormone-dependent gene expression, contributing to cervical carcinogenesis (Mitrani-Rosenbaum et al. 1989, Moodley et al. 2003, Baldwin et al. 2006). The major limitations of the studies mentioned in this section are that data suggesting the ability of oestrogen to increase LCR activity have been reported, and it has to be emphasised that there are no data indicating the direct involvement of functional EREs.

Another mechanism, linking oestrogen metabolism and polymorphisms in metabolising enzymes, was proposed to explain control over transcription of the HPV-integrated genome. Oestrogens are metabolised to 16- $\alpha$-hydroxy estrones that in turn covalently bind and activate ER $\alpha$. The activated ER $\alpha$ is assumed to bind to responsive elements within the LCR and further induce E6 and E7 transcription to maintain HPV gene activity (de Villiers 2003, Matos et al. 2016). Thus, it is hypothesised that both HPV and oestradiol enhance the effects of one another, either directly through functional EREs in the viral genome or indirectly encourage uncontrolled cellular proliferation and thereby promote malignant proliferation.

\section{In vivo studies indicate the requirement of oestrogens and ERs}

Animal studies have significantly demonstrated the requirement of oestrogens in an HPV-driven CC. Specifically, the role of oestrogens in HPV-related $\mathrm{CC}$ has been established in transgenic mouse models of CC (Herber et al. 1996, Brake \& Lambert 2005, Chung et al . 2008, 2013). Initially, the K14E6/E7 transgenic mouse was developed to study the roles of E6 and E7 in cervical carcinogenesis. In these mice, the ORF of E6/E7 is placed under the control of the human keratin promoter (K14) and directed to express E7 oncoproteins in the squamous epithelia, resembling a natural infection (Herber et al. 1996). This animal model developed ER $\alpha$-dependent CC upon treatment with subcutaneous implants of physiological levels of slow-release oestrogen tablets. In a study, K14E6/E7 transgenic mice were treated with oestrogen pellets for 9 months and developed cervical tumours with increased size compared to tumours that developed after 6 months of oestrogen treatment. When the oestrogen treatment was ceased for 3 months after an initial treatment of 6 months, the animal model developed significantly fewer, smaller and less aggressive tumours compared to animals treated for the complete 9 months. This study concluded that oestrogens play a critical role in the initiation, persistence and continued development of CC (Brake \& Lambert 2005). It was also shown that the cervical tumours that arise in K14E6/E7 transgenic mice could be prevented by treatment with ICI 182,780 and raloxifene (Chung \& Lambert 2009).

Interestingly, a group developed K14E7/ER $\alpha-/--$ knockout mouse by crossing K14E6/E7 mice with ER $\alpha-/--$ knockout mice. The resulting K14E7/ER $\alpha-/-$ mice failed to develop either cervical dysplasia or CC upon exogenous oestrogen treatment. None of the non-transgenic ER $\alpha-/-$ and $\mathrm{ER} \alpha+/+$ mice developed tumours, thereby indicating an important role for ER $\alpha$ at an early stage of cervical carcinogenesis (Chung et al. 2008). A study by Son and coworkers crossed a knock-in mouse model containing a mutant DNA-binding domain (Jakacka et al. 2002) with the K14E6/E7 transgenic mice. The resulting K14E6/E7 mouse line expressed a mutant DNA-binding domain in one of the alleles. Upon chronic oestrogen exposure, the mutant DNA-binding domain failed to bind to EREs and did not support oestrogen-induced epithelial cell proliferation and carcinogenesis. The study concluded that the ER $\alpha$ classical pathway is required for cervical carcinogenesis, and oestrogens may fail to cause CC in the absence of ERE (Son et al. 2014). The finding that oestrogens can provoke cervical tumours in HPV 16 K14E6/E7 transgenic mice is also consistent with other animal models such as HPV 18 URR E6/E7 transgenic mice (Park et al. 2003) and K14 HPV 16 transgenic mice, harbouring the entire HPV 16 early region under the control of the human keratin-K14 promoter (Elson et al. 2000).

Using the transgenic mouse with HPV-18-LCR-lacZ, which harbours the beta-galactosidase reporter gene under the control of the LCR promoter, exogenous administration of oestrogen and progesterone has been shown to effectively induce the expression of the transgene marker, mirroring LCR transcription. The LCR is known to drive HPV E6 and E7 transcription (GarciaCarranca et al. 1988). In addition, LCR-dependent transcription is specifically repressed with oestrogen and progesterone antagonists, indicating that the LCR may contain responsive elements sensitive to oestrogens (Morales-Peza et al. 2002). The strongest evidence for the role of oestrogen-ER $\alpha$ signalling in CC has been obtained from studies with HPV transgenic mice. This correlates well with the epidemiological data (Moreno et al. 2002, Muñoz et al. 2002, Marks et al. 2011, 2015, Liao et al. 2012, Roura et al. 2016), which indicate that long-term use of 
oral contraception and multiple pregnancies significantly increase the risk for CC in HPV-positive women.

\section{Studies using clinical specimens indicate a differential ERo expression pattern in the tumour epithelium}

Numerous studies with animal models have indicated that $\mathrm{ER} \alpha$ is required for the development of atypical squamous metaplasia, which has been proposed to be the first step of cervical carcinogenesis, before the development of CINs (mild, moderate and severe dysplasia). CIN I (mild) is a low-grade dysplasia. CIN II and III (moderate and severe dysplasia) are high-grade precancerous cervical lesions, which may progress to CC (http://screening.iarc.fr/doc/ colpochapter02.pdf, Chung et al. 2008, 2010, Chung \& lambert 2009). In clinical studies, contradictory findings were reported with regard to the relationship between $\mathrm{ER} \alpha$ expression and CC. In one instance, ER $\alpha$ and the progesterone receptor (PR) were found to be overexpressed in cervical adenocarcinoma. However, their expression did not demonstrate any prognostic significance (Bodner et al. 2010). Studies with patient-derived CC tissue samples have indicated a high expression of both ER $\alpha$ and PR in the normal epithelium of the transformation zone compared to the ectocervical epithelium in women of fertile age (Remoue et al. 2003). Positive ER $\alpha$ expression correlated with improved prognostic significance in CIN III lesions, and it has been suggested to serve as a useful marker in identifying a subset of patients with CIN III that have a low-risk for cancer progression, irrespective of the patient's age and HPV status (Fonseca-Moutinho et al. 2004). In another study, surgical tissue specimens collected from cervical carcinoma patients exhibited ER $\alpha$ (41\%) and PR (30\%) positivity. However, ER $\alpha$ expression did not correlate with survival time, whereas PR showed a weak correlation with survival time (Hunter et al. 1987). Masood and coworkers demonstrated ER $\alpha$ (30\%) and PR (35\%) positivity in adenocarcinoma specimens, and this positive expression status correlated with prolonged patient survival (Masood et al. 1993). Contrary to the above statement, the loss of ER $\alpha$ expression was established as an early alteration during the progression of cervical dysplasia to invasive carcinoma (Nonogaki et al. 1990, Konishi et al. 1991, Coelho et al. 2004, Zhai et al. 2010, López-Romero et al. 2013, Nikolaou et al. 2014). The majority of the basal cells in normal cervical tissue stained positive for ER $\alpha$, whereas the percentage of ER $\alpha$ expression was decreased in CIN and squamous cervical carcinoma to $31 \%$ and $11 \%$, respectively (Nikolaou et al. 2014). In contrast, PR expression tends to increase alongside CC progression with $29 \%$ for CIN and $49 \%$ for $\mathrm{CIN}$ and squamous cervical carcinoma. Indeed, Coelho and coworkers (Coelho et al. 2004) observed around $21 \%$ of cervical tumour biopsies to be ER $\alpha$ positive in the tumour epithelium. However, around 50\% ER $\alpha$ positivity was observed in the epithelium of the adjacent normal cervical tissue. Alternatively, PR expression was not detected in either a normal or tumour epithelium of any case studied. Coelho and coworkers concluded that the propensity of ER $\alpha$ distribution in normal tissue to be opposite that of lesions and underlined the importance of viral factors that affect the expression patterns of steroid receptors (Coelho et al. 2004). In a study, 93.7\% ERo expression was detected in the epithelium of normal cervical tissues but not in invasive cervical carcinomas (0\%) (López-Romero et al. 2013). This study concluded that the loss of ERo could have occurred, either due to post-transcriptional or post-translational regulation, given that $\mathrm{ER} \alpha \mathrm{mRNA}$ transcripts were detectable in both human normal and tumour tissues (López-Romero et al. 2013). Nonogaki and coworkers (Nonogaki et al. 1990) suggested that the specific HPV subtype of 16/18 could be responsible for ER $\alpha$ loss in CIN and invasive cervical carcinoma. Zhai and coworkers (Zhai et al. 2010) have also observed a loss of ER $\alpha$ expression during CC progression starting from CIN I and CIN II/III and continuing to invasive squamous cell carcinoma with 50, 15 and 3.7\% ER $\alpha$ positivity, respectively. In normal cervical tissue, Zhai and coworkers have observed $77 \%$ of ER $\alpha$ positivity, which is in line with the pattern observed by Coelho and coworkers (Coelho et al. 2004). Zhai and coworkers have also noted that there is no correlation between HPV status or HPV type with the loss of ER expression, which is contrary to Nonogaki and coworkers. Experiments with clinical tissue specimens have demonstrated that ER $\alpha$ is intact in the normal squamous cervical epithelium. However, it appears that after successful tumour initiation, epithelial ERo is no longer a requirement, and expression is lost during the progression to CINs and invasive carcinoma, suggesting a tumour-suppressive role for epithelial ERo in cervical carcinogenesis (Zhai et al. 2010, López-Romero et al. 2013, Nikolaou et al. 2014). Thus, only in vivo studies provide strong evidence regarding the continued expression of ER $\alpha$ to support the initiation and progression of CC (Chung \& Lambert 2009). However, it is worth noting that there is a paucity of recent data as well as inconsistencies related to sample size, HPV status, 
HPV subtype, histological grading of tumours and disease stage. Hence, ER $\alpha$ expression appears to be retained only in the normal cervical epithelium, but ER $\alpha$ stability during CC progression remains inconclusive.

\section{Maintenance of ER $\alpha$ expression in tumour stroma}

ER $\alpha$ is expressed in the normal cervical epithelium and expression continues to decline during the various phases of CC progression (Nonogaki et al. 1990, Konishi et al. 1991, Coelho et al. 2004, Zhai et al. 2010, López-Romero et al. 2013, Nikolaou et al. 2014). In contrast to this trend, stromal ERo is expressed in both normal and cervical tumour tissues (Mosny et al. 1989, Nonogaki et al. 1990, Coelho et al. 2004, López-Romero et al. 2013). Mosny and coworkers observed menstrual cycle-dependent changes in ER $\alpha$ concentration in the squamous epithelium of the uterine ectocervix, whereas invasive carcinomas were ER $\alpha$ negative. In normal, $\mathrm{CIN}$ and invasive squamous carcinomas of the uterine cervix, more than $50 \%$ of stromal cells were positive for ER $\alpha$. The level of stromal ER $\alpha$ was not influenced by the menstrual cycle. In addition, stroma in the normal cervix and CIN exhibited high positivity for PR (Mosny et al. 1989). López-Romero and coworkers (López-Romero et al. 2013) observed 93.7\% ER $\alpha$ positivity in stromal cells of the normal cervix. However, this study did not detail stromal $E R \alpha$ expression in CC specimens. Identical stromal ER $\alpha$ expression was observed in both the tumour and normal cervix at around $20.8-25 \%$. Similar findings were noted for PR expression in the stroma of normal and tumour tissue regardless of HPV status (Coelho et al. 2004). Nonogaki and coworkers (Nonogaki et al. 1990) clearly indicated the presence of ER $\alpha$-positive stromal cells surrounding the ER $\alpha$ negative tumour cells.

Chung and coworkers (Chung et al. 2008) compared ER $\alpha$ expression in both 17 $\beta$-oestradiol-treated K14E6/ E7 transgenic mice and human CC specimens. K14E6/ E7 transgenic mice developed tumours upon oestrogen treatment. Immunohistochemical analyses of mouse tumours revealed that $94 \%$ of cancer cells and $57 \%$ of stromal cells surrounding the cancers were positive for ER $\alpha$. As observed in the animal study, ER $\alpha$ was also expressed in human CC and the adjacent normal epithelia, as well as the surrounding stroma irrespective of HPV status (Chung et al. 2008).

The same group, using K14E7 transgenic mice, has demonstrated that stromal ER $\alpha$ signalling could trigger paracrine mechanisms, which are necessary for HPV-induced oestrogen-dependent cervical carcinogenesis. In this study, the mouse model with the E7 oncogene, under control of the human keratin 14 promoter, was made to express the E7 oncoprotein in the stratified squamous epithelia and engineered to express tamoxifen-inducible Cre recombinase, which can selectively delete ER $\alpha$ in the tumour stroma. Stromal ER $\alpha$ in this mouse model was temporally deleted with tamoxifen after 6 months of continuous oestrogen treatment. This deletion of ER $\alpha$ induced complete regression of cervical dysplasia, suggesting the importance of stromal ER $\alpha$ and its paracrine signalling mechanism in supporting tumour growth (Chung et al. 2013).

A recent study conducted with fresh human cervical tissue specimens (den Boon et al. 2015) has substantiated the findings of Chung and coworkers (Chung et al. 2013). ER $\alpha$ expression was observed to decline both at the mRNA and protein levels in the epithelium of normal cervical tissue, CINs and CC. However, ER $\alpha$ expression was maintained within the stromal compartment and became elevated throughout CC development. The authors concluded that, in spite of the decline of ER $\alpha$ in the tumour epithelium, the release of paracrine signalling pathways mediated through ER $\alpha$ from tumour-associated stromal fibroblasts might encourage CC progression (den Boon et al. 2015).

In another study, ex vivo CC-associated fibroblasts were isolated from human CC stroma and found to retain ER $\alpha$ expression. Cervical cancer-associated fibroblasts under the control of ER $\alpha$ signalling exhibited properties of promoting tumour growth by supporting cell proliferation, angiogenesis, metabolism, epithelialto-mesenchymal transition, epithelial cell migration and inflammation (Kumar et al. 2016). Kwasniewska and coworkers reported a strong expression of $\mathrm{ER} \alpha$ and PR in the stromal compartment of human CC specimens. Conversely, expression of both ER $\alpha$ and PR was decreased to undetectable levels in the tumour epithelium (Kwasniewska et al. 2011).

Unlike epithelial ER $\alpha$ that diminishes during CC progression (Nonogaki et al. 1990, Konishi et al. 1991, Coelho et al. 2004, Zhai et al. 2010, Nikolaou et al. 2014, den Boon et al. 2015), stromal ER $\alpha$ continues to persist during the course of CC progression (den Boon et al. 2015). Findings from both in vivo studies and experiments conducted with clinical specimens appear to be very consistent. Therefore, this evidence indicates the significance of stromal ER $\alpha$ and its crucial role in supporting cervical carcinogenesis. However, the exact 
mechanistic pathway of stromal ER $\alpha$ during the course of CC still needs to be deciphered. The role of stromal ERo in CC (Chung et al. 2013, den Boon et al. 2015) and its importance in general cancer progression has only recently gained prominence (Yamaguchi \& Sakai 2015). If the role of stromal ER $\alpha$ in CC is significant, targeting stromal ER $\alpha$ would be an excellent strategy to treat hormone-dependent CC.

\section{SERMs as potential therapeutic options}

The feasibility of selective estrogen receptor modulators (SERMs) as a therapeutic option in CC was studied only at the empirical level and has not been widely explored in a clinical setting. The anti-oestrogen raloxifene inhibited oestradiol-triggered transcription of HPV 16 E6/ E7 and suppressed the cell growth kinetics of CasKi cell lines (Ma et al. 2015). In a K14E6/E7 transgenic mouse model of HPV-induced CC, E6 and E7 oncoproteins were expressed in squamous epithelia under the control of the keratin promoter (K14), resembling a natural infection. These tumours retained functional ER $\alpha$ and responded to raloxifene and ICI 182,780 treatment. In addition, continuous treatment of mice with raloxifene prevented the reoccurrence of the disease compared to mice for whom the raloxifene treatment had been withdrawn (Chung \& Lambert 2009, Spurgeon et al. 2014).

Kumar and coworkers characterised CC-associated fibroblasts from early- to late-stage disease and performed ex vivo cell culture experiments. Subsequent to treatment with ICI 182,780 and methyl piperidino pyrazole, transcriptomic profiling of cultured samples revealed that these ER $\alpha$ inhibitors modulated the function of CC-associated stromal fibroblasts by downregulating genes associated with cell cycle, metabolism, angiogenesis and cancer progression. Stromal ER $\alpha$ target genes such as INPP4B, ESPL1, ORC1L, SERPINE1, SHC4 and MAP2K1 were consistently downregulated by both ER antagonists. This study emphasised the probable importance of SERMs to regulate stromal ER $\alpha$ signalling in CC (Kumar et al. 2016). To date, the majority of the information related to the possible utility of SERMs was obtained solely through in vitro and in vivo studies. The effectiveness of SERMs as therapeutics in CC is uncertain because of the lack of clinical evidence.

\section{Conclusion}

Accumulating evidence indicates the involvement of a synergistic combination between HPV infection status and a repeated surge of systemic increases in endogenous and exogenous oestrogens in the development of hormonedependent CC (Moreno et al. 2002, Muñoz et al. 2002, Marks et al. 2011, 2015, Liao et al. 2012, Roura et al. 2016). This association has been particularly well demonstrated in animal models (Herber et al. 1996, Brake \& Lambert 2005, Chung et al. 2008, 2013, Chung \& lambert 2009). The results obtained in studies with clinical specimens that pertain to the apparent gain or loss of ER $\alpha$ expression at various stages of disease progression needs further consideration. It is important to appreciate the dynamics of ER $\alpha$ expression, activation and interplay between epithelial and stromal ERo (Cunha et al. 2004, Yao et al. 2009, Rando et al. 2010) to exert control over the entire process of tumorigenesis. ER $\alpha$ has been known to show a spatio-temporal oscillatory pattern of activation, regardless of oestrogens or SERMs (Della Torre et al. 2011, Villa et al. 2012). Therefore, ER $\alpha$ expression in CC could possibly be a temporal event. Contradictory observations regarding the presence or absence of $\mathrm{ER} \alpha$ by different reports could be because of sampling in a snapshot of time window, during the entire duration of the disease, which involves varying degrees of amplitude, potency, type of oestrogen exposure, period of treatment and tissuespecific activation of different oestrogens (Rando et al. 2010). ER $\alpha$ supporting CC during the time of initiation of carcinogenic events indicate that ER $\alpha$ antagonists are a good therapeutic option at the onset of cervical carcinogenesis or the late maintenance of stromal ER $\alpha$, which needs to be targeted with a suitable SERM inhibitor. Although studies with animal models have demonstrated that SERMs are good candidates for treatment of CC, the current SERMs yielded inconclusive results (Chung et al. 2010, Castle 2011, Munger 2014) that limit their use because of a lack of evidence from controlled clinical trials. Hence, the efficacy and acceptance of SERMs as a therapeutic option in the precancer or invasive cervical carcinoma is largely unpredictable. Moreover, the practical feasibility of offering successful treatment by interfering with the synergistic function of oestrogens and HPV is largely unknown and needs to be studied further.

Next, it is important to note that most experimental studies were conducted using either HPV 16 or 18 sequences. This is due to the reason that HPV 16 and 18 are significantly established types and are responsible for causing 70\% of CC (http://www.who.int/mediacentre/ factsheets/fs380/en/). Studies with information related to the synergistic action of oestrogens linking with various high-risk HPV subtypes are yet to be evaluated. 
Additionally, there is no information available on the comparative considerations regarding the LCR of different HPV subtypes, other than the predominant HPVs (subtype 16 and 18) and the potential presence of oestrogen-binding sites. Availability of such data in the future may explain the functional relevance of interactions between oestrogens and specific HPV infection subtypes. Greater understanding of these interactions could help estimate the associated risk of developing CC. Few reports support the presence of partial or imperfect palindromes of responsive elements representing GREs and EREs (Garcia-Carranca et al. 1988, Mitrani-Rosenbaum et al. 1989, Chen et al. 1996, MoralesPeza et al. 2002, Burk et al. 2003, Moodley et al. 2003, Baldwin et al. 2006, López-Saavedra et al. 2009). However, these palindromes are only putative hormone-responsive element-like sequences. Although it can be presumed that cellular factors could bind to these sites for transactivating viral gene transcription, the continuity of recent data is lacking. Hence, it is difficult to predict the functional involvement of these responsive elements in the development of oestrogen-induced CC.

Based on the available literature (Park et al. 2003, de Villiers 2003, Brake \& Lambert 2005, Chung \& lambert 2009, Son et al. 2014, Spurgeon et al. 2014, Matos et al. 2016), there is a possibility that oestrogen might increase the level of E6/E7 mRNA. However, further evaluation is required. Alternatively, increase in HPV gene expression during the development of CC might also occur through an ER-independent mechanism or by altering the overall transcriptional machinery of HPV-infected cells and stimulating uncontrolled cellular proliferation.

Presently, it can be speculated that continued expression of ERo during the progression of $\mathrm{CC}$ is no longer a requirement in the tumour epithelium, and there is a shift in the ERo localisation from epithelial to stromal cells. The role of the continued presence of ER $\alpha$ in the tumour stroma in CC is only now gaining importance (den Boon et al. 2015). The exact mechanistic pathway used by stromal ER $\alpha$ to exert control over CC progression and its validity as a therapeutic target still need to be elucidated. It is vital to gain further insight into the functional molecular pathways involved between oestrogens, ER $\alpha$ and HPV oncogenes. Therefore, additional research in this field is warranted.

\section{Declaration of interest}

The author declares that there is no conflict of interest that could be perceived as prejudicing the impartiality of this review.

\section{Funding}

The author wishes to acknowledge the financial support from Science and Engineering Research Board (SB/YS/LS-49/2013).

\section{Acknowledgement}

The author wishes to thank S Namachivayam for his technical assistance.

\section{References}

Baldwin A, Huh KW \& Münger K 2006 Human papillomavirus E7 oncoprotein dysregulates steroid receptor coactivator 1 localization and function. Journal of Virology 80 6669-6677. (doi:10.1128/ JVI.02497-05)

Bodner K, Laubichler P, Kimberger O, Czerwenka K, Zeillinger R \& Bodner-Adler B 2010 Oestrogen and progesterone receptor expression in patients with adenocarcinoma of the uterine cervix and correlation with various clinicopathological parameters. Anticancer Research 30 1341-1345.

Brake T \& Lambert PF 2005 Estrogen contributes to the onset persistence and malignant progression of cervical cancer in a human papillomavirus-transgenic mouse model. PNAS 102 2490-2495. (doi:10.1073/pnas.0409883102)

Burk RD, Terai M, Gravitt PE, Brinton LA, Kurman RJ, Barnes WA, Greenberg MD, Hadjimichael OC, Fu L, McGowan L, et al. 2003 Distribution of human papillomavirus types 16 and 18 variants in squamous cell carcinomas and adenocarcinomas of the cervix. Cancer Research 63 7215-7220.

Castle PE 2011 Do selective estrogen receptor modulators treat cervical precancer and cancer? Time to pool data from relevant trials. International Journal of Cancer 128 997-998. (doi:10.1002/ijc.25393)

Chan WK, Klock G \& Bernard HU 1989 Progesterone and glucocorticoid response elements occur in the long control regions of several human papillomaviruses involved in anogenital neoplasia. Journal of Virology 63 3261-3269.

Chen YH, Huang LH \& Chen TM 1996 Differential effects of progestins and estrogens on long control regions of human papillomavirus types 16 and 18. Biochemical and Biophysical Research Communications 224 651-659. (doi:10.1006/ bbrc.1996.1080)

Chung SH \& Lambert PF 2009 Prevention and treatment of cervical cancer in mice using estrogen receptor antagonists. PNAS 106 19467-72. (doi:10.1073/pnas.0911436106)

Chung SH, Wiedmeyer K, Shai A, Korach KS \& Lambert PF 2008 Requirement for estrogen receptor alpha in a mouse model for human papillomavirus-associated cervical cancer. Cancer Research 68 9928-9934. (doi:10.1158/0008-5472.CAN-08-2051)

Chung SH, Franceschi S \& Lambert PF 2010 Estrogen and ERalpha: culprits in cervical cancer? Trends in Endocrinology and Metabolism 21 504-511. (doi:10.1016/j.tem.2010.03.005)

Chung SH, Shin MK, Korach KS \& Lambert PF 2013 Requirement for stromal estrogen receptor alpha in cervical neoplasia. Hormones and Cancer 4 50-59. (doi:10.1007/s12672-012-0125-7)

Coelho FRG, Prado JCM, Pereira Sobrinho JS, Hamada G, Landman G, Pinto CA, Nonogaki S \& Villa LL 2004 Estrogen and progesterone receptors in human papilloma virus-related cervical neoplasia. Brazilian Journal of Medical and Biological Research 37 83-88. (doi:10.1590/S0100-879X2004000100012)

Cunha GR, Cooke PS \& Kurita T 2004 Role of stromal-epithelial interactions in hormonal responses. Archives of Histology and Cytology 5 417-434. (doi:10.1679/aohc.67.417)

Della Torre S, Biserni A, Rando G, Monteleone G, Ciana P, Komm B \& Maggi A 2011 The conundrum of estrogen receptor oscillatory

Published by Bioscientifica Ltc. http://erc.endocrinology-journals.org

DOI: 10.1530/ERC-16-0571
(C) 2017 Society for Endocrinology Printed in Great Britain 
activity in the search for an appropriate hormone replacement therapy. Endocrinology 152 2256-2265. (doi:10.1210/en.2011-0173)

de Villiers EM 2003 Relationship between steroid hormone contraceptives and HPV cervical intraepithelial neoplasia and cervical carcinoma. International Journal of Cancer 103 705-708. (doi:10.1002/ijc.10868)

den Boon JA, Pyeon D, Wang SS, Horswill M, Schiffman M, Sherman M, Zuna RE, Wang Z, Hewitt SM, Pearson R, et al. 2015 Molecular transitions from papillomavirus infection to cervical precancer and cancer: role of stromal estrogen receptor signaling. PNAS 112 E3255-E3264. (doi:10.1073/pnas.1509322112)

Diel P 2002 Tissue-specific estrogenic response and molecular mechanisms. Toxicology Letters 1 217-224. (doi:10.1016/S03784274(01)00503-3)

Doorbar J, Egawa N, Griffin H, Kranjec C \& Murakami I 2015 Human papillomavirus molecular biology and disease association. Reviews in Medical Virology 25 (Supplement 1) 2-23. (doi:10.1002/rmv.1822)

Elson DA, Riley RR, Lacey A, Thordarson G, Talamantes FJ \& Arbeit JM 2000 Sensitivity of the cervical transformation zone to estrogen-induced squamous carcinogenesis. Cancer Research $\mathbf{6 0}$ $1267-1275$.

Fonseca-Moutinho JA, Cruz E, Carvalho L, Prazeres HJM, de Lacerda MMP, da Silva DP, Mota F \& de Oliveira CF 2004 Estrogen receptor progesterone receptor and bcl-2 are markers with prognostic significance in CIN III. International Journal of Gynecological Cancer $\mathbf{1 4}$ 911-920. (doi:10.1111/j.1048-891X.2004.14529.x)

Garcia-Carranca A, Thierry F \& Yaniv M 1988 Interplay of viral and cellular proteins along the long control region of human papillomavirus type 18. Journal of Virology 11 4321-4330.

Gierisch JM, Coeytaux RR, Urrutia RP, Havrilesky LJ, Moorman PG, Lowery WJ, Dinan M, McBroom AJ, Hasselblad V, Sanders GD, et al. 2013 Oral contraceptive use and risk of breast cervical colorectal and endometrial cancers: a systematic review. Cancer Epidemiology, Biomarkers and Prevention 22 1931-1943. (doi:10.1158/1055-9965. EPI-13-0298)

Henderson BE \& Feigelson HS 2000 Hormonal carcinogenesis. Carcinogenesis 3 427-433. (doi:10.1093/carcin/21.3.427)

Herber R, Liem A, Pitot H \& Lambert PF 1996 Squamous epithelial hyperplasia and carcinoma in mice transgenic for the human papillomavirus type 16 E7 oncogene. Journal of Virology $\mathbf{7 0}$ 1873-1881.

Hunter RE, Longcope C \& Keough P 1987 Steroid hormone receptors in carcinoma of the cervix. Cancer 60 392-396. (doi:10.1002/1097 0142(19870801)60:3<392::AID-CNCR2820600318>3.0.CO;2-C)

Jakacka M, Ito M, Martinson F, Ishikawa T, Lee EJ \& Jameson JL 2002 An estrogen receptor (ER)alpha deoxyribonucleic acid-binding domain knock-in mutation provides evidence for nonclassical ER pathway signaling in vivo. Molecular Endocrinology 10 2188-2201. (doi:10.1210/me.2001-0174)

King RJ 1991 Biology of female sex hormone action in relation to contraceptive agents and neoplasia. Contraception 6 527-542. (doi:10.1016/0010-7824(91)90002-W)

Klinge CM 2001 Estrogen receptor interaction with estrogen response elements. Nucleic Acids Research 29 2905-2919. (doi:10.1093/ nar/29.14.2905)

Konishi I, Fujii S, Nonogaki H, Nanbu Y, Iwai T \& Mori T 1991 Immunohistochemical analysis of estrogen receptors progesterone receptors Ki-67 antigen and human papillomavirus DNA in normal and neoplastic epithelium of the uterine cervix. Cancer $\mathbf{6 8}$ 1340-1350. (doi:10.1002/1097-0142(19910915)68:6<1340::AIDCNCR2820680626>3.0.CO;2-Q)

Kumar MM, Davuluri S, Poojar S, Mukherjee G, Bajpai AK, Bafna UD, Devi UK, Kallur PP, Kshitish AK \& Jayshree RS 2016 Role of estrogen receptor alpha in human cervical cancer-associated fibroblasts: a transcriptomic study. Tumor Biology 37 4409-4420. (doi:10.1007) s13277-015-4257-6)
Kwasniewska A, Postawski K, Gozdzicka-Jozefiak A, Kwasniewski W, Grywalska E, Zdunek M \& Korobowicz E 2011 Estrogen and progesterone receptor expression in HPV-positive and HPV-negative cervical carcinomas. Oncology Reports 26 153-160.

Lagunas-Martínez A, Madrid-Marina V \& Gariglio P 2010 Modulation of apoptosis by early human papillomavirus proteins in cervical cancer. Biochimica et Biophysica Acta 1805 6-16. (doi:10.1016/j. bbcan.2009.03.005)

Liao SF, Lee WC, Chen HC, Chuang LC, Pan MH \& Chen CJ 2012 Baseline human papillomavirus infection high vaginal parity and their interaction on cervical cancer risks after a follow-up of more than 10 years. Cancer Causes and Control 23 703-708. (doi:10.1007/ s10552-012-9939-4)

López-Romero R, Garrido-Guerrero E, Rangel-López A, ManuelApolinar L, Piña-Sánchez P, Lazos-Ochoa M, Mantilla-Morales A, Bandala C \& Salcedo M 2013 The cervical malignant cells display a down regulation of ER- $\alpha$ but retain the ER- $\beta$ expression. International Journal of Clinical and Experimental Pathology 6 1594-1602.

López-Saavedra A, González-Maya L, Ponce-de-León S, GarcíaCarrancá A, Mohar A \& Lizano M 2009 Functional implication of sequence variation in the long control region and E2 gene among human papillomavirus type 18 variants. Archives of Virology $\mathbf{1 5 4}$ 747-754. (doi:10.1007/s00705-009-0362-4)

Ma JQ, Wang XH, Tang LP, Chen XW \& Lou G 2015 Raloxifene suppress proliferation-promoting function of estrogen in CaSKi cervical cells. International Journal of Clinical and Experimental Medicine $\mathbf{8}$ $5571-5575$

Marks M, Gravitt PE, Gupta SB, Liaw KL, Kim E, Tadesse A, Phongnarisorn C, Wootipoom V, Yuenyao P, Vipupinyo C, et al. 2011 The association of hormonal contraceptive use and HPV prevalence. International Journal of Cancer 128 2962-2970. (doi:10.1002/ijc.25628)

Marks MA, Gupta S, Liaw KL, Tadesse A, Kim E, Phongnarisorn C, Wootipoom V, Yuenyao P, Vipupinyo C, Rugpao S, et al. 2015 Prevalence and correlates of HPV among women attending familyplanning clinics in Thailand. BMC Infectious Diseases 15159. (doi:10.1186/s12879-015-0886-z)

Masood S, Rhatigan RM, Wilkinson EW, Barwick KW \& Wilson WJ 1993 Expression and prognostic significance of estrogen and progesterone receptors in adenocarcinoma of the uterine cervix. An immunocytochemical study. Cancer 72 511-518. (doi:10.1002/10970142(19930715)72:2<511::AID-CNCR2820720230>3.0.CO;2-Q)

Matos A, Castelão C, Pereira da Silva A, Alho I, Bicho M, Medeiros R \& Bicho MC 2016 Epistatic interaction of CYP1A1 and COMT polymorphisms in cervical cancer. Oxidative Medicine and Cellular Longevity 2016 article 2769804. (doi:10.1155/2016/2769804)

Mitrani-Rosenbaum S, Tsvieli R \& Tur-Kaspa R 1989 Oestrogen stimulates differential transcription of human papillomavirus type 16 in SiHa cervical carcinoma cells. Journal of General Virology $\mathbf{7 0}$ 2227-2232. (doi:10.1099/0022-1317-70-8-2227)

Mittal R, Pater A \& Pater MM 1993 Multiple human papillomavirus type 16 glucocorticoid response elements functional for transformation, transient expression, and DNA-protein interactions. Journal of Virology 67 5656-5659.

Moodley M, Moodley J, Chetty R \& Herrington CS 2003 The role of steroid contraceptive hormones in the pathogenesis of invasive cervical cancer: a review. International Journal of Gynecological Cancer 13 103-110. (doi:10.1046/j.1525-1438.2003.13030.x)

Moody CA \& Laimins LA 2010 Human papillomavirus oncoproteins: pathways to transformation. Nature Review Cancer 10 550-560. (doi:10.1038/nrc2886)

Morales-Peza N, Auewarakul P, Juárez V, García-Carrancá A \& CidArregui A 2002 In vivo tissue-specific regulation of the human papillomavirus type 18 early promoter by estrogen progesterone and their antagonists. Virology 294 135-140. (doi:10.1006/ viro.2001.1287) 
Mosny DS, Herholz J, Degen W \& Bender HG 1989 Immunohistochemical investigations of steroid receptors in normal and neoplastic squamous epithelium of the uterine cervix. Gynecology \& Oncology 35 373-377.

Moreno V, Bosch FX, Muñoz N, Meijer CJ, Shah KV, Walboomers JM, Herrero R, Franceschi S \& International Agency for Research on Cancer. Multicentric Cervical Cancer Study Group 2002 Effect of oral contraceptives on risk of cervical cancer in women with human papillomavirus infection: the IARC multicentric case-control study. Lancet 359 1085-1092. (doi:10.1016/S0140-6736(02)08150-3)

Munger K 2014 Are selective estrogen receptor modulators SERMs a therapeutic option for HPV-associated cervical lesions and cancers? American Journal of Pathology 184 358-361. (doi:10.1016/j. ajpath.2013.11.005)

Münger K, Baldwin A, Edwards KM, Hayakawa H, Nguyen CL, Owens M, Grace M \& Huh K 2004 Mechanisms of human papillomavirus-induced oncogenesis. Journal of Virology $\mathbf{2 1}$ 11451-11460. (doi:10.1128/jvi.78.21.11451-11460.2004)

Muñoz N, Franceschi S, Bosetti C, Moreno V, Herrero R, Smith JS, Shah KV, Meijer CJ, Bosch FX \& International Agency for Research on Cancer. Multicentric Cervical Cancer Study Group 2002 Role of parity and human papilloma virus in cervical cancer: the IARC multicentric case-control study. Lancet 359 1093-1101. (doi:10.1016/ s0140-6736(02)08151-5)

Nikolaou M, Koumoundourou D, Ravazoula P, Papadopoulou M, Michail G \& Decavalas G 2014 An immunohistochemical analysis of sex-steroid receptors tumor suppressor gene p53 and Ki-67 in the normal and neoplastic uterine cervix squamous epithelium. Medicinski Pregled 67 202-207. (doi:10.2298/MPNS1408202N)

Nonogaki H, Fujii S, Konishi I, Nanbu Y, Ozaki S, Ishikawa Y \& Mori T 1990 Estrogen receptor localization in normal and neoplastic epithelium of the uterine cervix. Cancer 66 2620-2627. (doi:10.1002/1097-0142(19901215)66:12<2620::AIDCNCR2820661226>3.0.CO;2-S)

Park JS, Rhyu JW, Kim CJ, Kim HS, Lee SY, Kwon YI, Namkoong SE, Sin HS \& Um SJ 2003 Neoplastic change of squamo-columnar junction in uterine cervix and vaginal epithelium by exogenous estrogen in hpv-18 URR E6/E7 transgenic mice. Gynecologic Oncology 89 360-368. (doi:10.1016/S0090-8258(02)00106-3)

Ramachandran B, Stell A, Maravigna L, Maggi A \& Ciana P 2011 Novel insights on imaging sex-hormone-dependent tumourigenesis in vivo. Endocrine-Related Cancer 3 R41-R51. (doi:10.1530/ERC-10-0332)

Rando G, Horner D, Biserni A, Ramachandran B, Caruso D, Ciana P, Komm B \& Maggi A 2010 An innovative method to classify SERMs based on the dynamics of estrogen receptor transcriptional activity in living animals. Molecular Endocrinology 24 735-744. (doi:10.1210/ me.2009-0514)

Remoue F, Jacobs N, Miot V, Boniver J \& Delvenne P 2003 High intraepithelial expression of estrogen and progesterone receptors in the transformation zone of the uterine cervix. American Journal of Obstetrics and Gynecology 189 1660-1665. (doi:10.1016/S00029378(03)00852-4)

Roura E, Travier N, Waterboer T, de Sanjosé S, Bosch FX, Pawlita M, Pala V, Weiderpass E, Margall N, Dillner J, et al. 2016 The influence of hormonal factors on the risk of developing cervical cancer and pre-cancer: results from the EPIC cohort. PLOS ONE 11 e0147029. (doi:10.1371/journal.pone.0147029)

Schwarz E, Freese UK, Gissmann L, Mayer W, Roggenbuck B, Stremlau A \& zur Hausen H 1985 Structure and transcription of human papillomavirus sequences in cervical carcinoma cells. Nature $\mathbf{3 1 4}$ 111-114. (doi:10.1038/314111a0)

Senapati R, Senapati NN \& Dwibedi B 2016 Molecular mechanisms of HPV mediated neoplastic progression. Infectious Agents and Cancer 11 59. (doi:10.1186/s13027-016-0107-4)

Shai A, Pitot HC \& Lambert PF 2008 p53 Loss synergizes with estrogen and papillomaviral oncogenes to induce cervical and breast cancers. Cancer Research 68 2622-2631. (doi:10.1158/0008-5472.CAN-075266)

Sima N, Wang W, Kong D, Deng D, Xu Q, Zhou J, Xu G, Meng L, Lu Y, Wang S, et al. 2008 RNA interference against HPV16 E7 oncogene leads to viral E6 and E7 suppression in cervical cancer cells and apoptosis via upregulation of $\mathrm{Rb}$ and p53. Apoptosis 2 273-281. (doi:10.1007/s10495-007-0163-8)

Son J, Park JW, Lambert PF \& Chung SH 2014 Requirement of estrogen receptor alpha DNA-binding domain for HPV oncogene-induced cervical carcinogenesis in mice. Carcinogenesis 35 489-496. (doi:10.1093/carcin/bgt350)

Spurgeon ME, Chung SH \& Lambert PF 2014 Recurrence of cervical cancer in mice after selective estrogen receptor modulator therapy. American Journal of Pathology 184 530-540. (doi:10.1016/j. ajpath.2013.10.013)

Villa A, Della Torre S, Stell A, Cook J, Brown M \& Maggi A 2012 Tetradian oscillation of estrogen receptor $\alpha$ is necessary to prevent liver lipid deposition. PNAS 109 11806-11811. (doi:10.1073/ pnas.1205797109)

Yamaguchi H \& Sakai R 2015 Direct interaction between carcinoma cells and cancer associated fibroblasts for the regulation of cancer invasion. Cancers 7 2054-2062. (doi:10.3390/cancers7040876)

Yao L, Agoulnik AI, Cooke PS, Meling DD \& Sherwood OD 2009 Relative roles of the epithelial and stromal tissue compartment(s) in mediating the actions of relaxin and estrogen on cell proliferation and apoptosis in the mouse lower reproductive tract. Annals of the New York Academy of Sciences 1160 121-129. (doi:10.1111/j.1749-6632.2008.03799.x)

Zhai Y, Bommer GT, Feng Y, Wiese AB, Fearon ER \& Cho KR 2010 Loss of estrogen receptor 1 enhances cervical cancer invasion. American Journal of Pathology 177 884-895. (doi:10.2353/ajpath.2010.091166)

Received in final form 11 February 2017

Accepted 14 February 2017 http://erc.endocrinology-journals.org DOI: 10.1530/ERC-16-0571
๑ 2017 Society for Endocrinology Printed in Great Britain
Published by Bioscientifica Ltd 